\title{
КИНЕТИКА ЭЛЕКТРООСАЖДЕНИЯ И МОРФОЛОГИЯ ПОВЕРХНОСТИ КАДМИЕВЫХ И КАДМИЙОРГАНИЧЕСКИХ ПОКРЫТИЙ, СОДЕРЖАЩИХ Е-КАПРОЛАКТАМ
}

\author{
() 2017 Л. М. Скибина', О. А. Дуран Дельгадоㄹ, А. И. Соколенко ${ }^{2}$ \\ ${ }^{1}$ Южный федеральный университет, ул. Зорге, 7, 344090 Ростов-на-Дону, Россия \\ ${ }^{2}$ Донской государственный технический университет, \\ пл. Гагарина, 1, 344000 Ростов-на-Дону, Россия \\ e-mail:skibina@sfedu.ru \\ Поступила в редакцию 05.03.2017 г.
}

\begin{abstract}
Аннотация: Установлено, что в сульфатных электролитах кадмирования кинетика катодного процесса, микроструктура и свойства покрытий являются функцией природы и концентрации органических добавок, в качестве которых изучены $\varepsilon$-капролактам (КЛ), тетрагидрофуран (ТГФ) и пропиленкарбонат (ПК). Изменение состава жидкой фазы и введение в раствор циклического лактама, меняя условия сольватации, заметно сказываются на адсорбционных и координирующих свойствах компонентов электролита и, как следствие, на характере катодных процессов. Сравнением $3 d$-сканов поверхностей сформированных покрытий подтверждено образование металлполимерного покрытия на основе кадмия в присутствии КЛ. Расчет параметров решетки кадмия и кадмийорганического покрытия, содержащего КЛ, показал уменьшение среднего размера и объема зерен осадка.
\end{abstract}

Ключевые слова: электроосаждение, кинетика, хронопотенциометрия, морфология, поверхность, покрытия, комплексообразование, адсорбция.

\section{ВВЕДЕНИЕ}

При изучении процессов электрохимического выделения металлов в присутствии различных поверхностно-активных веществ (ПАВ) интерес представляет природа адсорбированных на электроде (свободные молекулы или комплексные соединения ионов металлов с ПАВ, растворителем, анионами) и восстанавливающихся частиц (простые ионы или адсорбированные комплексы). Актуальность этой проблеме придает широкое использование различных органических добавок для эффективного регулирования скорости процесса и качества металлических покрытий [1-7].

Известно, что введение органических добавок в электролиты позволяет формировать качественные покрытия без существенного снижения скорости электродного процесса. В смешанных водноорганических растворах увеличивается число разнообразных по природе и прочности комплексных ионов, что расширяет рабочий диапазон электролита. Свойства смешанных систем, наряду с изменившимися условиями массопереноса, сольватации и адсорбции компонентов электролита на электроде, открывают новые возможности для дальнейшей интенсификации процессов получения покрытий, в том числе композиционных, с заданным комплексом свойств [1]. Включенные в структуру осадка дисперсные частицы позволяют целенаправленно модифицировать физические и антикоррозионные свойства пленок, что существенно улучшает эксплуатационные характеристики покрытий [2]. Особый интерес представляют циклические лактамы, способные электрохимически полимеризоваться на электроде при соосаждении с металлами и формировать металлополимерные покрытия [3], сочетающие свойства как металлов (электро- и теплопроводность, твердость, термостойкость), так и полимеров (пластичность, коррозионная стойкость, антифрикционные свойства).

При рассмотрении кинетики электровосстановления ионов металла необходимо учитывать возможность влияния адсорбированных на электроде комплексов с поверхностно-активными анионами на скорость и механизм реакций. Так, ускорение электродного процесса при избытке иодидионов при электроосаждении кадмия связывается 
с электровосстановлением адсорбированных комплексов $\mathrm{CdI}_{3}^{-}$и обусловлено облегчением переноса электрона через анионы I-, которые являются мостиковыми лигандами вследствие наличия у них вакантных 5d-орбиталей [8]. Подобного рода механизм ускоряющего действия I- при электровосстановлении ионов кадмия в присутствии тетрабутиламмония, N,N-диметилформамида (ДМФА), диметилсульфоксида и других ПАВ наблюдали также авторы работ [9-11], что указывает на общность механизма ускоряющего действия анионов $\mathrm{I}^{-}$как в чистых электролитах, так и содержащих органические добавки.

Несколько иной механизм ускорения электродного процесса имеет место при избытке ионов $\mathrm{Cd}^{2+}$. В этих условиях, по мнению авторов [12], peализуются случай, когда реагирующий комплекс образуется непосредственно в двойном слое в результате как электростатического, так и более глубокого взаимодействия ионов $\mathrm{Cd}^{2+} \mathrm{c}$ адсорбированными ионами йода. Последнее должно в значительной степени зависеть от локального $\psi^{\prime}$-потенциала, создаваемого адсорбированными анионами. Фрумкин [13] отмечает, что при таком комплексообразовании снижается гидратация и увеличивается растворимость реагирующих частиц в поверхностном слое, вследствие чего возрастает скорость, и снижается энергия активации разряда.

В работе [14] отмечается аналогия в действии микроколичеств анионов галоидов и тиомочевины (TM) на кинетику разряда ионов кадмия. Однако при избытке ТМ, в отличие от иодидных сред, адсорбированные комплексы кадмия с органическими лигандами $\left[\mathrm{Cd}(\mathrm{TM})_{2}\right]^{2+}$ восстанавливаются при значительно более высоких перенапряжениях. Вероятно, из-за стерических препятствий ускоренный перенос электрона через атом серы молекулы ТМ в адсорбированных комплексах становится невозможным. Последнее, однако, не относится к комплексам $[\mathrm{Cd}(\mathrm{TM})]^{2+}$ и свободным молекулам TM, которые действуют при электровосстановлении катионов металлов как мостиковые лиганды, обеспечивающие наиболее эффективный путь для переноса электрона от катода к реагирующим катионам. По-видимому, механизм ускоряющего действия иодид-ионов и ТМ при избытке катионов металла аналогичен и связан с образованием в двойном электрическом слое промежуточных комплексов катионов $\mathrm{Cd}^{2+}$ с адсорбированными мостиковыми лигандами.

Данные о кинетике и механизме разряда ионов в растворах переменного состава представляет зна- чительный интерес не только для теории элементарного акта электродных реакций, но и при разработке практически важных систем для электрохимического осаждения и соосаждения технически значимых металлов. В литературе нет единого мнения о причинах существенного влияния состава водно-органического раствора на кинетику и механизм разряда ионов металлов. В согласии с [15], это обусловлено изменением устойчивости и химической природы комплексных частиц и электролите. В [16], наряду с перестройкой координационной сферы иона, существенная роль отводится адсорбции компонентов раствора на электроде. Резкое изменение скорости катодного процесса в смешанных электролитах связывается также с изменением структурных свойств жидкой фазы, приводящим к изменению энергетического состояния иона в растворе [17].

Важную роль в кинетике процесса электровосстановления ионов металлов в смешанных электролитах играет конкурирующая адсорбция молекул воды и органической добавки на электродной поверхности. Возможность и степень вытеснения дипольных молекул воды в двойном слое молекулами органической добавки зависит от ряда факторов, в том числе и от анионного состава электролита. Чем выше способность аниона вступать в ковалентную связь с поверхностными атомами металла, тем значительнее должна быть ингибирующая адсорбция органических веществ на электроде [18]. Согласно [19], замещение воды затрудняется с повышением энергии гидратации анионов, особенно при положительном заряде поверхности металла, когда анионы преобладают в ионной обкладке двойного слоя. Такой механизм действия поверхностно-активных анионов на эффективность органических добавок путем стабилизации воды на электродной поверхности применен для интерпретации данных по влиянию анионного состава электролита на кинетику электроосаждения кадмия из водно-органических растворов [20]. Увеличение степени затрудненности процесса с ростом температуры, наблюдаемое в перхлоратном электролите, свидетельствует об изменении природы разряжающихся на катоде ионов и может быть связано с полной заменой молекул воды в сольватной оболочке иона молекулами ДМФА с образованием более прочных катионов типа $\left[\mathrm{Cd}(Д М Ф А){ }_{4}\right]^{2+}$. Следует заметить, что качество Cd-покрытий (мелкокристалличность, адгезия, внешний вид) улучшается в ряду анионов $\mathrm{F}^{-}, \mathrm{CH}_{3} \mathrm{CO}_{2}^{-}$, $\mathrm{ClO}_{4}^{-}$, I- .

Представленный обзор показывает, что на сегодняшний день достаточно подробно изучены пер- 
хлоратные $[1,10]$ и йодидные $[1,8-11]$ водные и водно-органические системы. Тогда как поведение циклических органических соединений в сульфатных электролитах требует дополнительного изучения, чтобы судить об общих закономерностях их влияния на катодный процесс и морфологию поверхности. А именно эти системы наиболее часто используются в практических целях для формирования электрохимических покрытий на основе кадмия.

Изучение процессов адсорбции на границе раздела катод-электролит [21] и комплексообразования в сульфатных электролитах кадмирования [22] позволило выявить отчетливую зависимость кинетических параметров процесса, состава и триботехнических свойств металлорганического покрытия от концентрации N-метилпирролидона и производного анилина [21]. Химические превращения циклических органических соединений могут происходить как с раскрытием цикла, так и без него. Раскрытие цикла возможно в случае проведения кислотного или щелочного гидролиза, алкоголиза или полимеризации. Условия протекания данных реакций зависят от размера цикла, а также от количества и положения заместителей. Полимеризация таких веществ протекает под действием катализаторов катионного и анионного типов, в случае лактамов легче всего полимеризуются семи- и девятичленные циклы [23], поэтому электрохимическая полимеризация КЛ при его соосаждении с кадмием должна протекать эффективнее, чем в случае $\mathrm{N}$-метилпирролидона.

Цель настоящей работы заключается в изучении влияния природы и концентрации добавок циклических органических соединений на кинетические параметры процесса электровосстановления ионов $\mathrm{Cd}^{2+}$, а также особенностей соосаждения кадмия с $\varepsilon$-капролактамом, микроструктуру и некоторые характеристики полученных осадков.

\section{ЭКСПЕРИМЕНТАЛЬНАЯ ЧАСТЬ}

В качестве объекта исследования при хронопотенциометрических измерениях использовали сульфатный электролит, содержащий $10^{-2}$ моль/л $\mathrm{CdSO}_{4}+0.1$ моль/л $\mathrm{Li}_{2} \mathrm{SO}_{4}$. В качестве органических компонентов использовали $\varepsilon$-капролактам, тетрагидрофуран и пропиленкарбонат в широком диапазоне концентраций: от $10^{-2}$ до 1 моль/л. Использовали бидистиллят и химически чистые реактивы. Все электрохимические измерения проводили в атмосфере электролитического водорода при 298 К в трехэлектродной ячейке, в качестве анода исполь- зовалась кадмиевая пластина. Электрод сравнения - насыщенный хлоридсеребряный.

Хронопотенциограммы (ХПГ) снимали на платиновом электроде площадью $1 \mathrm{~cm}^{2}$, который перед каждым опытом обезжиривали этиловым спиртом, промывали в проточной воде, высушивали и затем в течение десяти минут покрывали кадмием из стандартного электролита при плотности тока $12 \mathrm{~mA} / \mathrm{cm}^{2}$. Состав стандартного электролита кадмирования (г/л): $\mathrm{CdSO}_{4}-60$; $\left(\mathrm{NH}_{4}\right)_{2} \mathrm{SO}_{4}-30$; $\mathrm{A} 1_{2}\left(\mathrm{SO}_{4}\right)_{3}-25$. Электролиз проводили в гальваностатическом режиме в стеклянной ячейке объемом $100 \mathrm{~cm}^{3}$. После опыта покрытие стравливали в разбавленной (1:1) $\mathrm{HNO}_{3}$. В качестве регистрирующего прибора использовали потенциостат-гальваностат «P-8nano» (Elins), с помощью которого записывали $E$, $\tau$-кривые при включении импульса тока величиной от 4 до $8 \mathrm{~mA} / \mathrm{cm}^{2}$. Методика оценки и расчета переходного времени описаны в [24].

Емкость и сопротивление двойного электрического слоя определяли, как описано в работе [11]. Методика определения кадмия в покрытии приведена в [25].

Исследования поверхности образцов проводили с помощью сканирующего зондового микроскопа (C3M) Solver P47 (NT-MDT) в прерывисто-контактном режиме, т.к. данный режим позволяет свести к минимуму воздействие кантилевера на нанообъект.

Статистическая обработка экспериментальных данных проводилась с использованием коэффициента Стьюдента при доверительной вероятности 0.95 по методике малых выборок (ГОСТ Р ИСО 5725-1-2002).

\section{РЕЗУЛЬТАТЫ И ИХ ОБСУЖДЕНИЕ}

Для определения кинетики процесса использовали диагностические критерии, обычно применяемые в хронопотенциометрии [26], для этого эксперименты проводили в релаксационном режиме на платиновом электроде, покрытом свежеосажденным кадмием. Поляризацию кадмиевого катода $\Delta E=E_{0}-E_{i}$ (где $E_{0}$ и $E_{i}-$ бестоковый потенциал и потенциал электрода под током соответственно) находили по осциллограммам «потенциал-время», на которых при всех изученных плотностях поляризующего тока $i$ и концентрациях добавок $c_{L}^{0}$ имелась единственная волна восстановления ионов кадмия. Линейный характер графиков $\Delta E-\lg i$ (рис. 1) свидетельствует о том, что для всех изученных систем и во всем изученном интервале концентраций органических веществ $c_{L}^{0}$ в начальные 


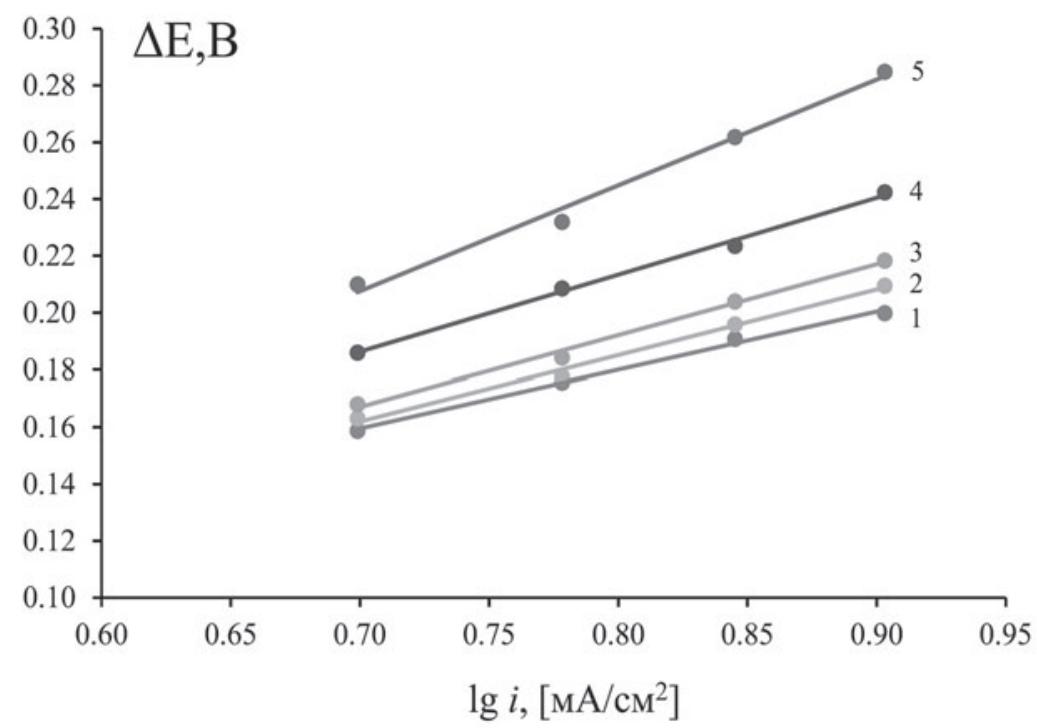

Рис. 1. Зависимость поляризации $\Delta E$ электровосстановления ионов $\mathrm{Cd}^{2+}$ от логарифма плотности поляризующего тока lgi в сульфатном электролите без добавки (1) и с добавками ТГФ $c_{L}^{0}$ (моль/л): 10-2 (2); $0.1(3) ; 0.5$ (4); 1 (5) [Fig. 1. Polarization $\Delta E$ of electroreduction of $\mathrm{Cd}^{2+}$ ions as a function of current density logarithm $\lg i$ in sulfate electrolyte with tetrahydrofuran additive at a concentration (mol/l): 0 (1); 10-2(2); 0.1(3); 0.5 (4); 1 (5)]

моменты времени скорость определяющей стадией электродного процесса является электрохимическая стадия разряда-десольватации. С течением времени в приэлектродной зоне происходят концентрационные изменения, и процесс описывается уравнением [27]:

$i \tau^{\frac{1}{2}}=\frac{1}{2} z F \pi^{\frac{1}{2}} D_{\text {диф }}^{\frac{1}{2}} C^{0}\left\{1-\frac{i}{k C^{0}} \exp -\left[\frac{\alpha z F\left(\Delta E-E_{p}\right)}{R T}\right]\right\}$.

Из рис. 1 следует, что переход к электролитам, содержащим ТГФ, сопровождается ростом поляризации катодного процесса. Аналогичный характер зависимостей в тафелевых координатах был отмечен в электролитах, содержащих КЛ и ПК.

Анализ зависимости $\tau$ от $i$ показал, что по достижении переходного времени в отсутствие добавок величина $i \tau^{1 / 2}$ для водного сульфатного электролита не изменяется с увеличением $i$ (рис. 2, кривая 1). Известно [26], что произведение $i \tau^{1 / 2}$ является независимым от $і$ при неизменной концентрации деполяризатора, электровосстановление которого происходит в условиях полубесконечной линейной диффузии.

Введение в электролит добавок и увеличение их концентрации меняют не только скорость, но и механизм электродного процесса. В области концентраций $\varepsilon$-капролактама $c_{L}^{0}>0.1$ моль/л произведение $i \tau^{1 / 2}$ резко снижается с ростом $i$ (рис. $2 a$, кривые 6, 7). Согласно [28] это является следстви- ем преимущественного участия в электродной реакции достаточно прочных комплексов $\mathrm{Cd}^{2+}$ с молекулами добавок, разряду которых предшествует их «вынужденная» диссоциация по мере проникновения через адсорбционный слой на поверхности катода. При низких концентрациях $\varepsilon$-капролактама произведение $i \tau^{1 / 2}$ слабо зависит от $i$ (рис. $2 a$, кривые 2-4), но прослеживается тенденция к снижению переходного времени с увеличением концентрации добавки. В случае электролитов, содержащих ТГФ и ПК, изменения кинетических параметров с ростом $C_{L}{ }^{\circ}$ во многом аналогичны КЛ, но проявляются не так явно (рис. $2 b, c)$ : также наблюдается снижение произведения $i \tau^{1 / 2}$ при высоких концентрациях добавки, изменяется угол наклона зависимости $i \tau^{1 / 2}$ к $i$ (рис. $2 c$, кривыле 4-5), что, возможно, связано с изменением состава формирующихся в растворе и участвующих в разряде комплексов кадмия.

Обработка хронопотенциометрических данных позволила определить основные кинетические параметры электродного процесса, а также рассчитать коэффициенты диффузии потенциалопределяющих ионов, зависимость которых от $c_{L}^{0}$ представлена на рис. 3 .

Появление экстремумов на зависимостях основных кинетических параметров электродной реакции (ток обмена и коэффициент переноса) в присутствии КЛ от $c_{L}^{0}$ (рис. $3 a, b$, кривая 1$)$ подтверж- 

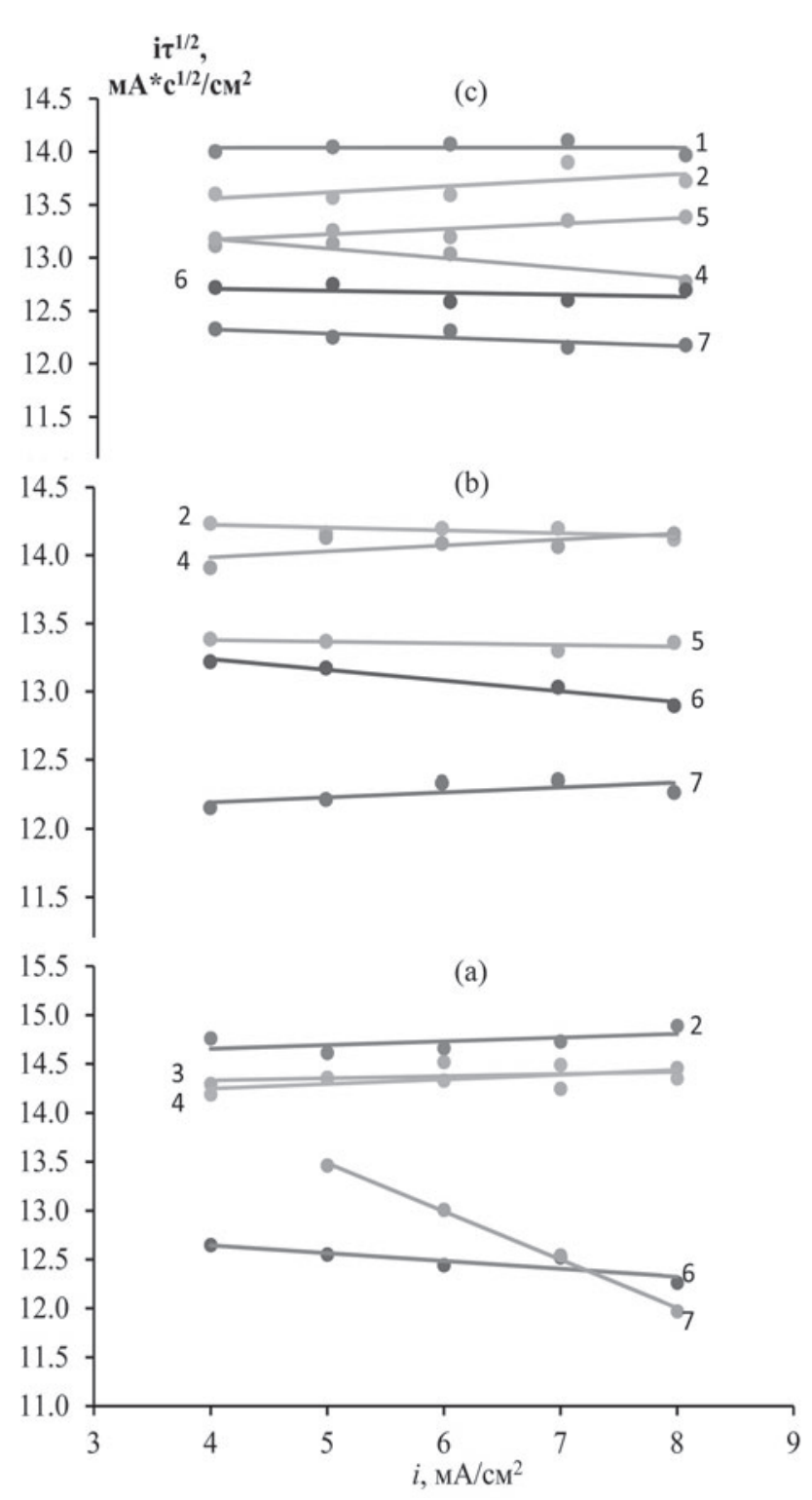

Рис. 2. Зависимость произведения $i \tau^{1 / 2}$ от плотности тока $i$ в сульфатном электролите, содержащем $\varepsilon$-КЛ $(a)$, ТГФ $(b)$ и ПК (c) при $c^{0}$ моль/л: $0(1) ; 10^{-2}(2) ; 5 \cdot 10^{-2}(3)$; 0.1 (4); 0.2 (5); 0.5 (6); 1 (7).

[Fig 2. $i \tau^{1 / 2}$ as a function of current density $i$ in sulfate electrolyte containing caprolactam $(a)$, tetrahydrofuran $(b)$, propylene carbonate $(c)$ at a concertation (mol/l): 0 (1); $10^{-2}(2) ; 5 \cdot 10^{-2}(3) ; 0.1$ (4); 0.2 (5); 0.5 (6); 1 (7)]

дает изменение кинетики при изменении концентрации добавки. По-видимому, при $c_{L}^{0}<0.1$ моль/л в разряде на катоде участвуют предварительно адсорбированные комплексы катионов кадмия с молекулами КЛ, а при $c_{L}^{0}>0.1$ моль/л прочность этих комплексов возрастает и процесс контролируется их замедленной предшествующей разряду диссоциацией. Эти процессы должны способствовать включению лактама в состав покрытия. При этом увеличивается коэффициент эффективности КЛ (рис. 3c, кривая 1). Несмотря на сложный характер полученных зависимостей, экстремумы на графиках совпадают. Это подтверждает кинетический характер затруднений при протекании реакции электровосстановления ионов $\mathrm{Cd}^{2+}$. Величины $\alpha$ изменяются в пределах от 0.08 до 0.13 (рис. $3 b$ ), что хорошо согласуется с литературными данными для сходных систем [27].

Восходящий характер зависимостей произведения $i \tau^{1 / 2}$ с ростом $i$ в интервале низких концентраций ТГФ (рис. $2 b)$ и ПК (рис. 2c) позволил рассчитать концентрацию Г предварительно адсорбированных на электроде комплексных форм. Эта величина при определенных концентрациях добавок была рассчитана из графиков в координатах $i \tau-\tau^{1 / 2}$ (рис. 4).

Линеаризация зависимости переходного времени $\tau$ от $i$ в этих координатах для водно-тетрагидрофуранового электролита (рис. 4) указывает на одновременное восстановление адсорбированных электроактивных комплексов (ЭАК) $\mathrm{Cd}^{2+}$ с ТГФ и диффундирующих из объема раствора ионов. Существование таких комплексов в изученных системах косвенно подтверждается снижением коэффициентов диффузии потенциалопределящих ионов $D$ при переходе от фонового электролита к электролитам, содержащим добавки, и с ростом концентрации добавки, например, в присутствии ТГФ от $6.7 \cdot 10^{-5}$ до $5.1 \cdot 10^{-5} \mathrm{~cm}^{2} /$ с (рис. 3d, кривая 2).

При изучении кинетики электродных процессов необходимо учитывать характер взаимодействия с электродом ЭАК, непосредственно участвующих в электрохимической стадии. Ранее В. И. Кравцовым [29] на основе анализа внешнесферных и внутрисферных механизмов электродных превращений были сформулированы критерии, позволяющие судить о механизме электродных реакций ЭАК. Показано, что основными факторами влияния на кинетику процесса с участием ЭАК могут быть как реорганизация внешней координационной сферы комплекca, так и перестройка электронных структур внутрисферных комплексов с возможной перезарядкой ЭАК. Возможно, с такой перестройкой структур связано изменений кинетики в присутствии КЛ.

В зависимости от природы лигандов, наличия в них мостиковых атомов или групп и их ориентации относительно поверхности электрода адсорбция комплексов может приводить как к ускорению, так и к торможению электродных процессов. В присутствии КЛ наблюдается рост гиббсовой адсорб- 
(b)

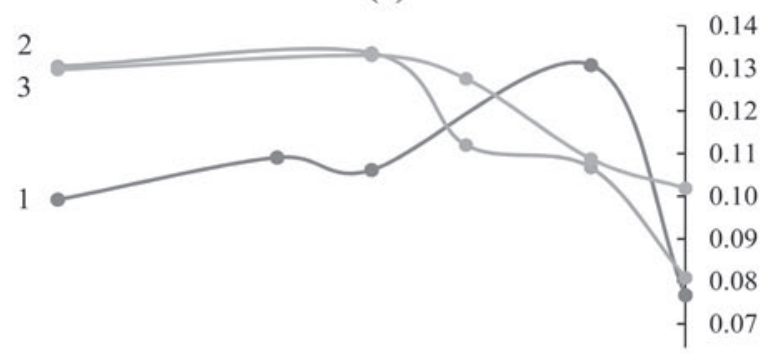

(a)

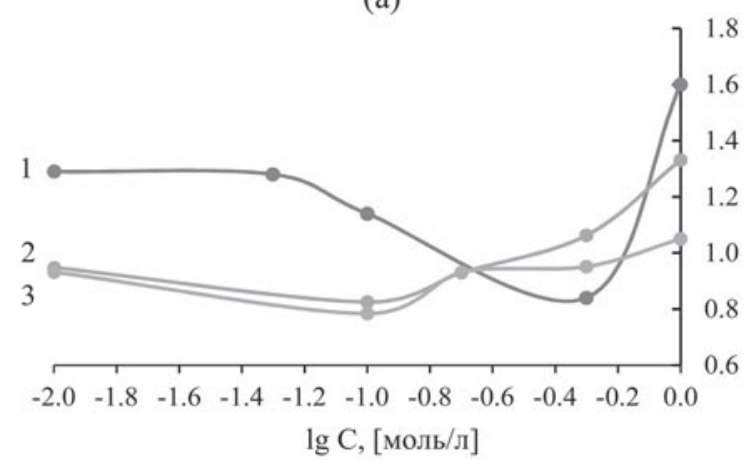

(c)

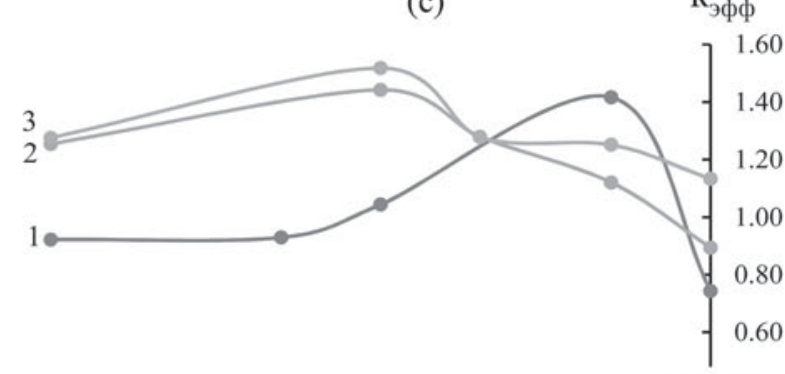

(d)

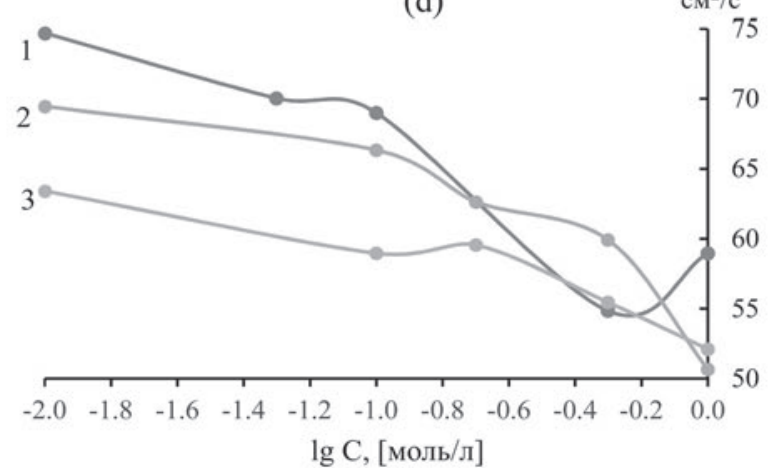

Рис. 3. Зависимость тока обмена $i^{0}$ реакции разряда ионов кадмия $(a)$, коэффициента переноса $\alpha(b)$, коэффициен-

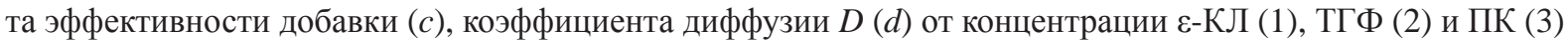

[Fig. 3. Exchange current $i^{0}$ of cadmium ion electroreduction $(a)$, charge transfer coefficient $\alpha(b), K_{\text {eff }}$ efficiency factor of the additive $(c)$, mass diffusivity $D(d)$ as a function of concentration of caprolactam additive]

ции электроактивных комплексов Г от $1.1 \cdot 10^{-9}$ до $4.5 \cdot 10^{-9}$ моль/см² при увеличение $c_{L}^{0}$ КЛ от $10^{-2}$ до 0.1 моль/л. Увеличение адсорбции ЭАК сопровождается снижением скорости электродной реакции, а рост концентрации свободных молекул КЛ в поверхностном слое к ускорению процесса (рис. $3 a$, кривая 1). Об адсорбции лактама на кадмии судили по данным импедансных измерений, результаты которых представлены на рис. 5. Ранее [30] уже было отмечено ускоряющее действие КЛ на электровосстановление кадмия из перхлоратных сред, которое может быть связано с облегчением переноса электронов через молекулы КЛ, входящие в состав ЭАК и являющиеся мостиковыми лигандами.

При добавлении тетрагидрофурана происходит незначительное снижение адсорбции ЭАК от $4.0 \cdot 10^{-9}$ до $3.1 \cdot 10^{-9}$ моль/см² в интервале концентраций $c_{L}^{0}$ от $10^{-1}$ до 1.0 моль/л, в случае ПК аналогичное уменьшение наблюдается в более широкой области концентраций добавки. Эти факты свидетельствуют о том, что особенности формирования и прочность ЭАК зависят от природы органической добавки и ее концентрации в объеме электролита и на поверхности. Согласно полученным данным наибольшей прочностью отличаются ЭАК катионов кадмия с КЛ, что, по-видимому, является ос-

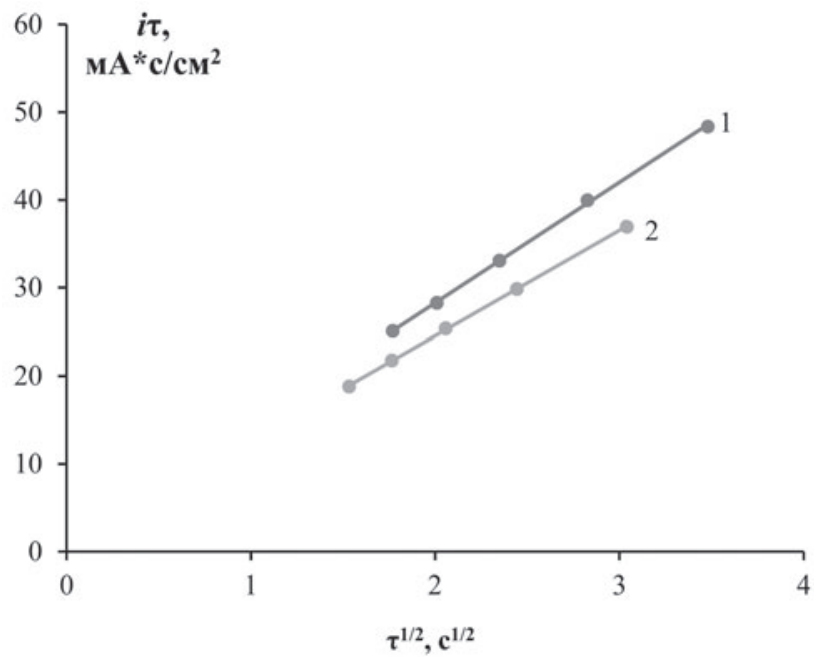

Рис. 4. Зависимость произведения i $\tau$ от корня квадратного из переходного времени $\tau^{1 / 2}$ в сульфатном электролите с добавкой ТГФ при $c_{L}^{0}$, моль/л: 0.1 (1); 1 (2)

[Fig. 4. $i \tau$ as a function on the square root of transient time $\tau^{1 / 2}$ in sulfate electrolyte with tetrahydrofuran additive at a concentration (mol/l): 0.1 (1); 1 (2)]

новной причиной отмеченного ранее включения его в состав металлического осадка [30].

Для кадмия характерна высокая гидрофильность и сравнительно низкая адсорбционная активность, поэтому конкурентная адсорбция молекул воды, 


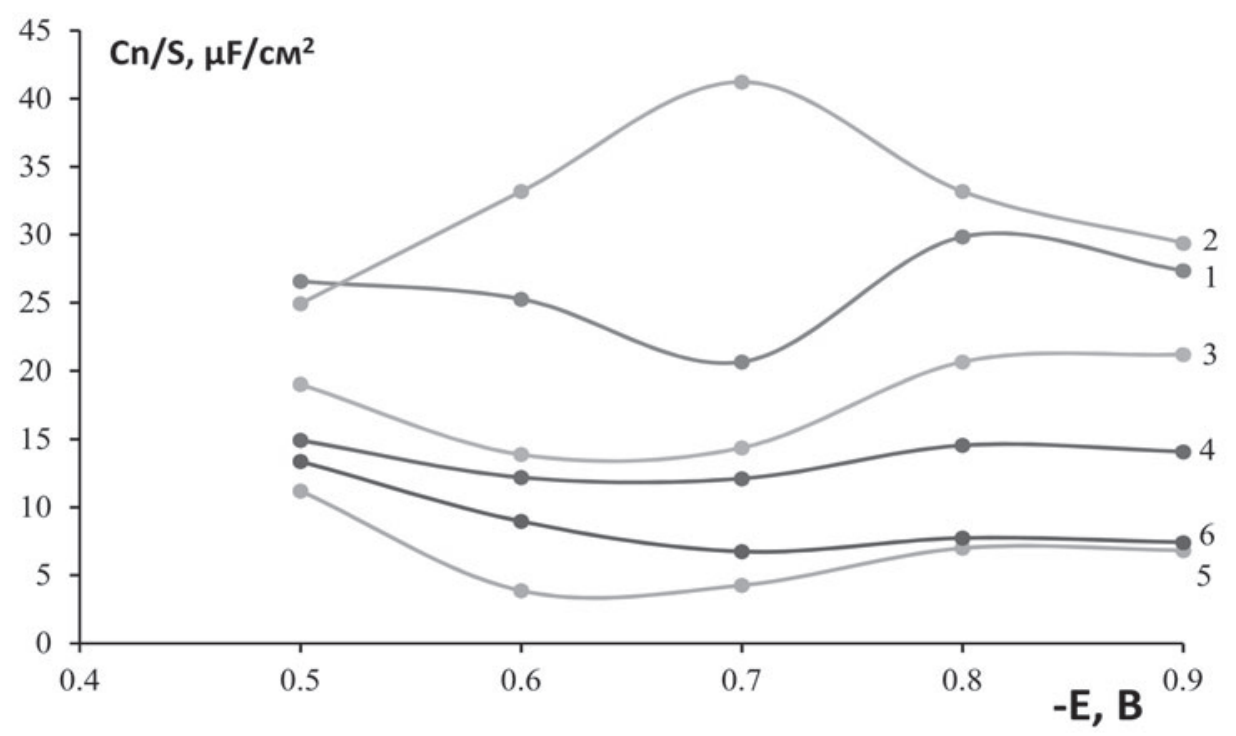

Рис. 5. Кривые дифференциальной емкости $C_{n} / S$ кадмиевого катода в сульфатном электролите (1) в присутствии $\varepsilon$-капролактама при $c_{\text {кл }}^{0}$ (моль/л): $10^{-2}(2) ; 5 \cdot 10^{-2}(3) ; 0.1(4) ; 0.5$ (5); 1 (6)

[Fig. 5. Differential capacitance curves $C_{n} / S$ of cadmium cathode in sulfate electrolyte containing caprolactam additive (mol/l): 0 (1); $10^{-2}(2) ; 5 \cdot 10^{-2}(3) ; 0.1$ (4); 0.5 (5); 1 (6)]

анионов и органической добавки должна оказывать значительное влияние на процесс электровосстановления ионов металла. Учитывая положительный заряд поверхности Cd по отношению к раствору [20], можно ожидать, что в ионном слое электрода будут преобладать анионы, а адсорбция ПАВ зависеть от их способности вытеснять молекулы воды и анионы с поверхности катода. Как известно [18], это вытеснение затрудняется с повышением энергии гидратации анионов, которая особенно велика у анионов $\mathrm{SO}_{4}^{2-}$. О конкурентном характере адсорбции может свидетельствовать увеличение емкости кадмиевого электрода и появление максимума на емкостной кривой при переходе от фонового раствора к электролиту, содержащему КЛ в минимальной концентрации $10^{-2}$ моль/л (рис. 5, кривая 2).

Можно полагать, что увеличение емкости электрода и появление максимума имеют одну общую причину, которая заключается в наложении на емкость двойнослойного конденсатора дополнительной емкости, связанной с процессами адсорбции сульфат-анионов. В области $C_{L}^{0}>0.05$ моль/л поверхностная концентрация молекул КЛ возрастает: наблюдается снижение емкости при потенциалах осаждения кадмия (рис. 5, кривая 3). Антибатный характер зависимостей Г и декремента емкости $(\Delta C)$ от $c_{L}^{0}$ позволяет предположить, что в разряде из адсорбированного состояния участвуют комплексы $\mathrm{Cd}^{2+}$ с молекулами КЛ, сформировавшиеся в растворе, а не на электродной поверхности.

Снижение величины адсорбции Г в присутс- твии ТГФ и ПК по мере увеличения $c_{L}^{0}$ обусловлено, вероятно, десорбирующим действием молекул добавки. В пользу сказанного говорит и тот факт, что увеличение концентрации свободного лиганда $c_{L}^{0}>0.1$ моль/л приводит к изменению природы замедленной стадии процесса: из-за упрочнения комплексных частиц появляется предшествующая разряду медленная химическая стадия их диссоциации по мере проникновения через адсорбционный слой, состоящий из молекул добавки. По-видимому, по мере проникновения разряжающихся ионов через адсорбционный слой, состоящий из молекул органической добавки, молекулы воды в сольватной оболочке иона замещаются на молекулы добавки. Об этом свидетельствует линейное снижение произведения $i \tau^{1 / 2}$ с увеличением $i$ (рис. 2, кривые 6 и 7).

Одновременное увеличение декремента емкости (рис. 6a), связанное с ростом адсорбции КЛ на кадмии, и уменьшение содержание кадмия в покрытии (рис. 6b) с ростом $c_{L}^{0}$ подтверждает включение лактама, установленное ранее методом РСФА [31].

Исследование топологии поверхностей металлорганических пленок методом АСМ в прерывисто-контактном режиме с одновременной визуализацией рельефа и фазового контраста показало различие в составах анализируемых поверхностей пленок, сформированных из фонового электролита и электролита с КЛ (рис. 7).

Сравнение сканов поверхности (3D) чистого 


\section{Cd, \%}

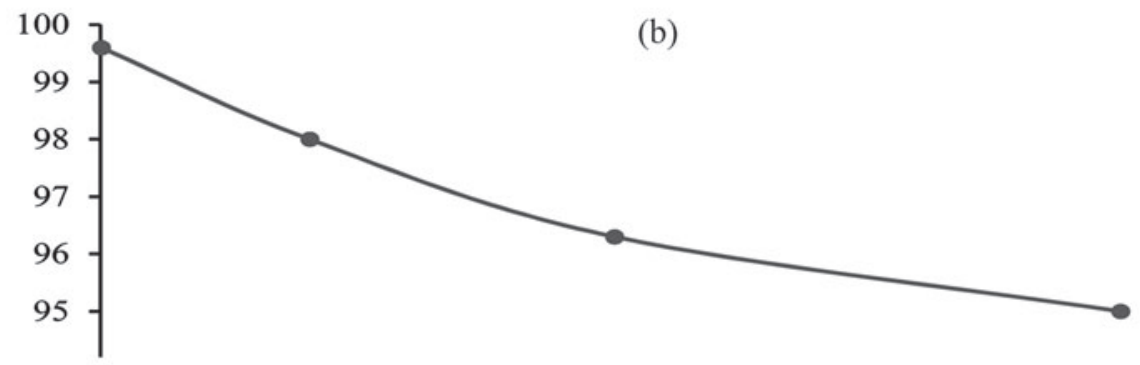

$\Delta \mathrm{C}, \boldsymbol{\mu F} / \mathbf{c m}^{2}$

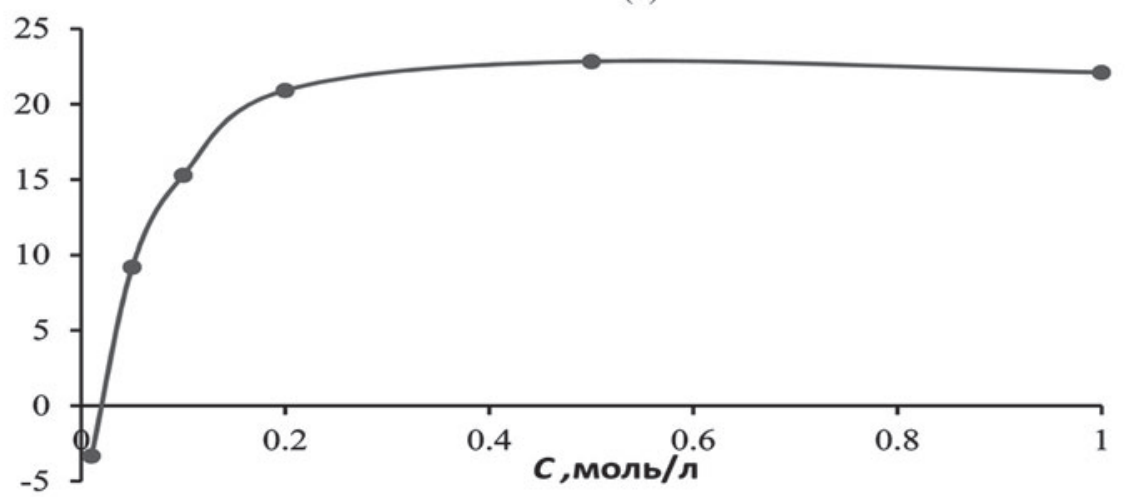

Рис. 6. Зависимость декремента емкости кадмиевого катода при $E=-0.8$ В в 0.1 молярном растворе $\mathrm{Li}_{2} \mathrm{SO}_{4}(a)$ и зависимость содержания кадмия в покрытии $(b)$ от концентрации $\varepsilon$-капролактама в сульфатном электролите

[Fig. 6. Capacitance decrement of cadmium cathode at $E=-0.8 \mathrm{~V}$ in the solution with molar concentration $0.1 \mathrm{~mol} / \mathrm{l}$ of $\mathrm{Li}_{2} \mathrm{SO}_{4}(a)$ and cadmium content in the coating depending on the concentration of caprolactam in the sulfate electrolyte $(b)]$
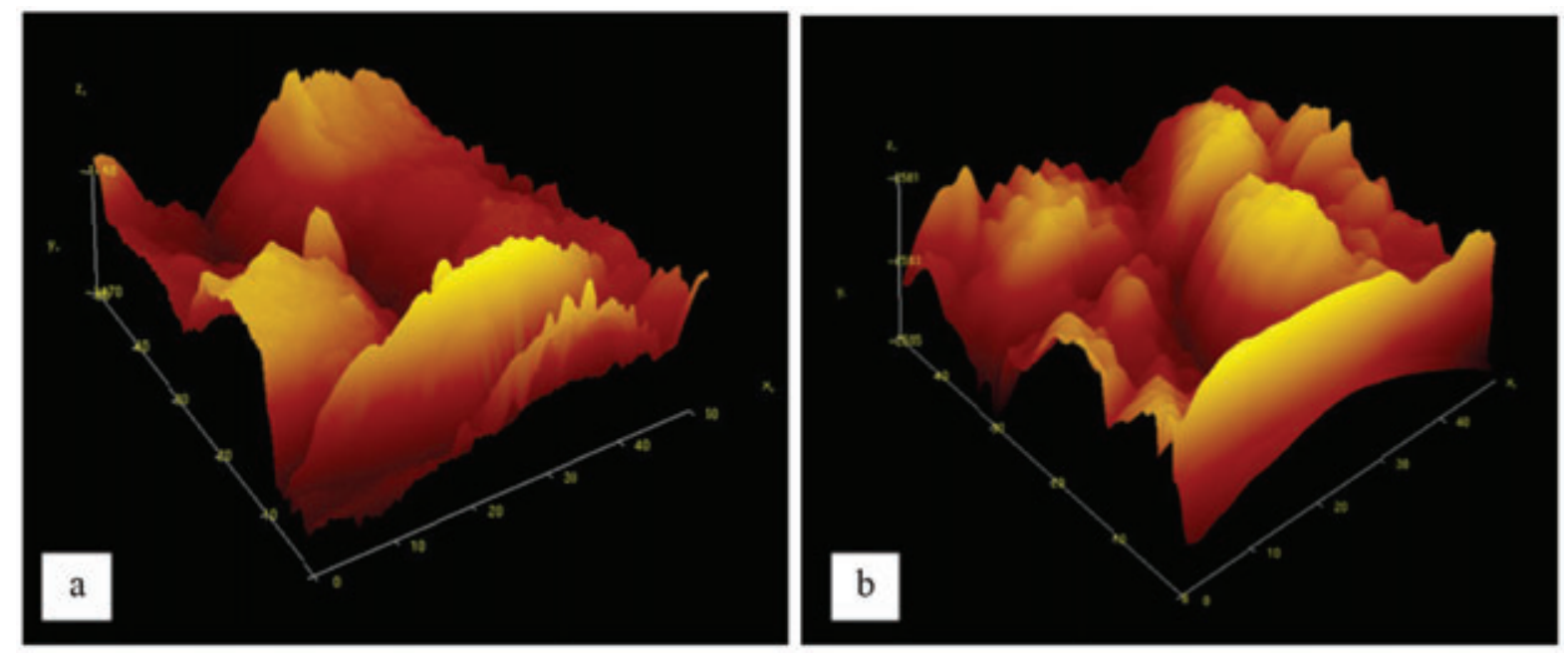

Рис. 7. Топография кадмиевых покрытий, полученных из фонового сульфатного электролита кадмирования (a); электролита с содержанием $\varepsilon$-КЛ $c_{L}^{0}=1.0$ моль/л $(b)$

[Fig. 7. Surface images of cadmium coatings obtained from standard electrolyte $(a)$ in the presence of caprolactam additive at a concentration, mol/l: $1.0(b)]$ 
кадмия (рис. $7 a$ ) и металлорганического покрытия (рис. 7b) позволяет заметить существенные изменения в структуре осадков - размерах зерен и однородности поверхности. В случае металлического осадка ярко выражены крупные зерна, возможно, обусловленные неравномерностью подложки. При изменении состава пленки происходит слияние островков металла и полимера, что приводит к образованию сплошного сглаженного слоя. Это является подтверждением образования нового материала в ходе процесса электроосаждения из раствора, содержащего КЛ.

C помощью программы Gwyddion были проанализированы данные С3М (рис. 7a, b). Согласно результатам, полученным при использовании программы Gwyddion, видно, что при введении в сульфатный электролит кадмирования КЛ при $c_{L}^{0}=1$ моль/л, размер зерна уменьшается с 2.01 до 1.08 мкм (табл.), что способствует формированию более плотного слоя на поверхности электрода и должно приводить к улучшению функциональных свойств покрытий.

Таблица. Зависимость параметров решетки металла от присутствия КЛ в электролите

[Table. Metal lattice parameters as a function of the caprolactam concentration in the electrolyte]

\begin{tabular}{|c|c|c|}
\hline $\begin{array}{c}\text { Параметр } \\
\text { [Parameters] }\end{array}$ & $\begin{array}{c}\text { Фоновый } \\
\text { электролит } \\
\text { [Standard } \\
\text { electrolyte] }\end{array}$ & $\begin{array}{c}C_{L}^{\text {o }}=1 \text { моль/л } \\
{\left[C_{L}^{\text {o }}=1 \mathrm{~mol} / \mathrm{l}\right]}\end{array}$ \\
\hline $\begin{array}{c}\text { Средняя площадь зерна } \\
\text { Average area of crystallite }\end{array}$ & $50.0 \mu \mathrm{m}^{2}$ & $3.8 \mu \mathrm{m}^{2}$ \\
\hline $\begin{array}{c}\text { Средний размер зерна } \\
\text { Average size of crystallite }\end{array}$ & $2.01 \mu \mathrm{m}$ & $1.08 \mu \mathrm{m}$ \\
\hline $\begin{array}{c}\text { Общий объем зерна } \\
\text { Overall volume } \\
\text { of crystallite }\end{array}$ & $1.52 \cdot 10^{-15} \mathrm{~m}^{3}$ & $0.69 \cdot 10^{-15} \mathrm{~m}^{3}$ \\
\hline
\end{tabular}

\section{ЗАКЛЮЧЕНИЕ}

Установлено, что в присутствии $\varepsilon$-капролактама уже при низких концентрациях происходит формирование на поверхности электрода адсорбционной пленки, состоящей из анионов и адсорбированных электроактивных комплексов лактама с $\mathrm{Cd}^{2+}$, что приводит к незначительному торможению реакции. Рост концентрации $\varepsilon$-капролактама $c_{L}^{0}>0.1$ моль/л, когда содержание лактама в 10 раз превосходит концентрацию потенциалопределяющих ионов $\mathrm{Cd}^{2+}$, наряду с адсорбционными явлениями на границе раздела фаз усиливаются процессы комплексообразования в объеме электролита. Именно при этих концентрациях происходит соосаждение кадмия с капролактамом, который включается в металлическую матрицу. Можно полагать, что в рассматриваемых системах предшествующая разряду химическая стадия соответствует диссоциации формирующихся в сульфатном растворе комплексов катионов кадмия с КЛ переменного состава.

Показано, что циклические органические соединения, используемые в качестве альтернативных ПАВ, оказывают схожее влияние на скорость и основные кинетические параметры процесса. В отличие от экстремальных зависимостей, полученных в присутствии КЛ, в основном, характер зависимостей параметров электродного процесса от концентрации ТГФ и ПК монотонны. Расчет параметров решетки чистого кадмия и металлорганического покрытия показал уменьшение среднего размера и объема зерен осадка, сформированного в присутствии $\varepsilon$-капролактама.

\section{СПИСОК ЛИТЕРАТУРЫ}

1. Кузнецов В. В., Скибина Л. М. Природа растворителя и строение лиганда при элекроосаждении металлов. Изд-во Южного федерального университета, 2009, 367 с.

2. Целуйкин В. Н. // Физикохимия поверхности и защита материалов, 2009, т. 45, № 3, с. 287-301.

3. Смирнов В. А., Сухоленцев Э. А., Кузнецов В. В. и др. // Защита металлов, 1992, т. 28, № 5, с. 811-815.

4. Капица М. // Технологии в электронной промышленности, 2006, № 2, с. 20-24.

5. Saha S., Taguchi T., Tachikawa N., Yoshii K., Katayama Y. // Electrochimica Acta, 2015, vol. 183, pp. 4248.

6. Dolati A., Afshar A., Ghasemi H. // Materials Chemistry and Physics, 2005, vol. 94(1), pp. 23-28.

7. Hamilakis S., Balgis D., Milonakou-Koufoudaki K., Mitzithra C., Kollia C., Loizos Z. // Materials Letters, 2015, vol. 145, pp. 11-14.

8. Лошкарев Ю. М., Варгалюк В. Ф. // Электрохимия, 1977, т. 13, № 9, с. 1321-1326.

9. Кузнецов В. В., Боженко Л. Г., Кучеренко С. С. и др. // Электрохимия, 1988, т. 24, № 5, с. 633-639.

10. Kuznetsov V. V., Skibina L. M., Mikheeva M. A. // Protection of Metals and Physical Chemistry of Surfaces, 2011, vol. 47, № 2, pp. 220-224.

11. Кузнецов В. В., Скибина Л. М., Лоскутникова И. Н. и др. // Защита металлов, 1998, т. 34, № 5, c. 521-526.

12. Лошкарев Ю. М., Варгалюк В. Ф. Двойной слой и адсорбиия на твердых электродах. Тарту, 1975, c. $158-167$.

13. Фрумкин А. Н. Основные вопросы современной теоретической электрохимии. Мир, 1965, с. 302-317.

14. Лошкарев Ю. М. // Электрохимия, 1973, т. 9, № 9, c. 1302-1305. 
15. Тихонов К. И., Заболоцкий В. И., Вольтер Д. // Электрохимия, 1974, т. 10, № 6, с. 985-987.

16. Байбарова Е. Я., Емельяненко Г. А., Куклева Л. А. // Ж. неорг. химии, 1975, т. 20, № 12, с. 3194 3198.

17. Кузнецов В. В., Федорова О. В. Ингибирование и пассивирование металлов. Изд-во Ростовского государственного университета, 1976, с. 181-185.

18. Лошкарев Ю. М. // Защитта металлов, 1972, т. 8, № 2, c. 163-167.

19. Лошкарев М. А., Лошкарев Ю. М., Кудина И. П. // Электрохимия, 1977, т. 13, № 5, с. 715-720.

20. Кузнецов В. В., Скибина Л. М., Левочкин Р. А., Вертий И. В. // Защчита металлов, 2003, т. 39, № 2, c. 176.

21. Skibina L.M., Burdina E. I., Sokolenko A. I. // Protection of Metals and Physical Chemistry of Surfaces, 2012. vol. 48, № 4, pp. 449-454.

22. Skibina L. M., Burdina E. I., Dorogan I. V., Bumber A. A. // Russian Journal of Electrochemistry, 2013, vol. 49, № 2, pp. 124-130.
23. Новиков А. Н., Ленина О. Ф., Василёв В. А. // Химия и химическая технология, 2009, т. 52, № 4, c. 20.

24. Делахей П. Новые приборы и методы в электрохимии. Изд-во иностр. литературы, 1957, 612 с.

25. Вячеславов, П. М. Новые электрохимические покрытия. Изд-во Лениздат, 1972, 145 с.

26. Захаров М. С., Баканов В. И., Пнев В. В. Хронопотенциометрия. Химия, 1978, 11 с.

27. Байбарова Е. Я., Емельяненко Г. А., Куклева Л. А. // Укр. химич. журнал, 1974, т. 40, № 2, с. 163.

28. Кравцов В. И. Электродные прочессы в растворах комплексов металлов. Изд-во ЛГУ, 1969, 192 с.

29. Кравцов В. И. // Успехи химии, 1976, т. 45, № 4, c. 579.

30. Кузнецов В. В., Скибина Л. М., Соколенко А. И. // Физикохимия поверхности и защчтта материалов, 2004, т. 40, № 4, с. 348 .

31. Мазурицкий М. И., Дуймакаев Ш. И., Скибина Л. М. // Поверхность. Рентгеновские, синхротронные и нейтронные исследования, 2014, № 8, с. 38.

\title{
ELECTRODEPOSITION KINETICS AND THE SURFACE MORPHOLOGY OF CADMIUM AND CADMIUM-ORGANIC COATINGS CONTAINING E-CAPROLACTAM
}

\author{
() 2017 L. M. Skibina1 ${ }^{\text {, O. A. Duran Delgado¹ }{ }^{1} \text { A. I. Sokolenko² }}$ \\ ${ }^{1}$ Southern Federal University, Faculty of Chemistry, 7 Zorge str., 344090 Rostov-on-Don, Russia \\ ${ }^{2}$ Don State Technical University, 1 Gagarin's sq., 344000 Rostov-on-Don, Russia \\ e-mail: skibina@sfedu.ru
}

Received: 05.03.2017

\begin{abstract}
Metal polymeric coverings are of special interest as a new class of materials that have the properties of both metals and polymers. Unfortunately, information about the similar coverings electrodeposition and the mechanism of transformation taking place in a solution or at electrode surface is quite limited. We investigated the influence of caprolactam (CPL), tetrahydrofuran (THF) and propylene carbonate (PC) additives on the kinetics of cathodic processes in the cadmium sulfate electrolyte, microstructure and the grain size of metal and metal-polymeric deposits. The addition of cyclic lactam changes adsorption and coordination properties of the electrolyte components, the type of cathodic process and leads to a considerable improvement in their structure and physicalmechanical characteristics.

Using chronopotentiometry analysis with impedance data, it was found that the real electroactive species formed in aqueous-organic mixtures determine the electrodeposition kinetics due to complexation of discharging metal ions with adsorbed molecules of additives. It was established the $\varepsilon$-caprolactam addition resulted in the growth of cathodic polarization $\Delta \mathrm{E}$ the value of which depends on the volume concentration $c_{L}^{0}$

According to the polarization and impedance measurements, an increase in $C_{L}^{0}$ intensifies the participation of organic molecules, first in the adsorption process at the Cd-cathode $\left(c_{L}^{0} \leq 0.1 \mathrm{M}\right)$ and then in the complexion with cadmium ions in the solution volume $\left(c_{L}^{0}>0.1 \mathrm{M}\right)$. In the latter case, elecroactive particles that are formed in the solution take place in electrodeposion reactons which leads to increased CPL content in the Cd-covering. The influence of THF and PC results in a slight increase of exchange current and coefficient $b_{c}$ and a decrease of diffusion coefficient $D$ and transfer coefficient $\alpha$.
\end{abstract}


The codeposition of metal with polymer leads to a significant decrease in the grain volume and size of metal inclusions. A comparison of the $3 D$ scans of the surface of the obtained coatings verified the formation of the cadmium based metal-polymer coatings in presence of CPL. Varying the electrolyte composition and technological conditions of plating makes it possible to control both the metalpolymer ratio in the coating and the grain sizes of the metallic phase in the formed metal-polymeric films.

Keywords: electrodeposition, kinetics, chronopotentiometry, morphology, surface, coatings, complexation, adsorption.

\section{REFERENCES}

1. Kuznetsov V. V., Skibina L. M. Nature of the Solvent and the Structure of the Ligand in the Electroplating of Metals. Southern Federal University Publ., 2009, p. 367. (in Russian)

2. Tseluikin V. N. Protection of Metals and Physical Chemistry of Surfaces, 2009, vol. 45, no. 3, pp. 287-301.

3. Cmirnov V. A., Sukholentsev E. A., Kuznetsov V. V., et al. Protection of Metals, 1992, vol. 28, no. 5, pp. 811815.

4. Kapitsa M. Technologies in Electronic Industry, 2006, no. 2, pp. 20-24.

5. Saha S., Taguchi T., Tachikawa N., Yoshii K., Katayama Y. Electrochimica Acta, 2015, vol. 183, pp. 42-48. https://doi.org/10.1016/j.electacta.2015.05.018

6. Dolati A., Afshar A., Ghasemi H. Materials Chemistry and Physics, 2005, vol. 94(1), pp. 23-28. https://doi. org/10.1016/j.matchemphys.2005.03.057

7. Hamilakis S., Balgis D., Milonakou-Koufoudaki K., Mitzithra C., Kollia C., Loizos Z. Materials Letters, 2015, vol. 145, pp. 11-14. https://doi.org/10.1016/j.matlet.2015.01.052

8. Loshkarev Yu. M., Vargalyuk V. F. Russian Journal of Electrochemistry, 1977, vol. 13, no. 9, pp. 1321-1326.

9. Kuznetsov V. V., Bozhenko L. G., Kucherenko S. S., et al. Russian Journal of Electrochemistry, 1988, vol. 24, no. 5, pp. 633-639.

10. Kuznetsov V. V., Skibina L. M., Mikheeva M. A. Protection of Metals and Physical Chemistry of Surfaces, 2011, vol. 47, no. 2, pp. 220-224. https://doi.org/10.1134/ S2070205111010102

11. Kuznetsov V. V., Skibina L. M., Loskutnikova I. N., et al. Protection of Metals, 1998, vol. 34, no. 5, pp. 521526.

12. Loshkarev Yu. M., Vargalyuk V. F. Double Layer and Adsorption on Solid Electrodes. Tartu Publ., 1975, pp. 158-167. (in Russian)

13. Frumkin A. N. The Main Questions of Modern Theoretical Electrochemistry, Mir Publ., 1965, pp. 302-317. (in Russian)

14. Loshkarev Yu. M. Russian Journal of Electrochemistry, 1973, vol. 9, no. 9, pp. 1302-1305.

15. Tikhonov K. I., Zabolotskii V. I., Vol’ter D. Russian Journal of Electrochemistry, 1974, vol. 10, no. 6, pp. 985987.
16. Baibarova E. Ya., Emel'yanenko G. A., Kukleva L. A. Russian Journal of Inorganic Chemistry, 1975, vol. 20, no. 12, pp. 3194-3198.

17. Kuznetsov V. V., Fedorova O. V. Inhibiting and Passivating Metals. Rostov State University, Publ., 1976, pp. 181-185. (in Russian)

18. Loshkarev Yu. M. Protection of Metals, 1972, vol. 8, no. 2, pp. 163-167.

19. Loshkarev M. A., Loshkarev Yu. M., Kudina I. P. Russian Journal of Electrochemistry, 1977, vol. 13, no. 5, pp. 715-720.

20. Kuznetsov V. V., Skibina L. M., Levochkin R. A., Vertiy I. V. Protection of Metals, 2003, vol. 39, no. 2, pp. 176-181.

21. Skibina L. M., Burdina E. I., Sokolenko A. I. Protection of Metals and Physical Chemistry of Surfaces, 2012. vol. 48, no. 4, C. 449-454. https://doi.org/10.1134/ S2070205112040168

22. Skibina L. M., Burdina E. I., Dorogan I. V., Bumber A. A. Russian Journal of Electrochemistry, 2013, vol. 49, no. 2, pp. 124-130. https://doi.org/10.1134/ S102319351302016X

23. Novikov A. N., Lenina O. F., Vasilev V. A. Chemistry and Chemical Technology, 2009, vol. 52, no. 4, p. 20.

24. Delakhei P. New Devices and Methods in Electrochemistry. Inostr. Literatury Publ., 1957, 612 p. (in Russian)

25. Vyacheslavov, P. M. New Electrochemical Coatings. Lenizdat Publ., 1972, 145 p. (in Russian)

26. Zakharov M. S., Bakanov V. I., Pnev V. V. Chronopotentiometry. Chemistry Publ., 1978, 11 p. (in Russian)

27. Baibarova E. Ya., Emel'yanenko G. A., Kukleva L. A. Ukr. Chem. Journal, 1974, vol. 40, no. 2, p. 163.

28. Kravtsov V. I. Electrode Processes in Solutions of Metal Complexes. Leningrad State University Publ., 1969, 192 p. (in Russian)

29. Kravtsov V. I. Russian Chemical Reviews, 1976, vol. 45, no. 4, p. 579.

30. Kuznetsov V. V., Skibina L. M., Sokolenko A. I. Protection of Metals and Physical Chemistry of Surfaces, 2004, vol. 40, no. 4, p. 348.

31. Mazuritskii M. I., Duimakaev Sh. I., Skibina L. M. Journal of Surface Investigation: X-Ray, Synchrotron and Neutron Techniques, 2014, no. 8, p. 38. https://doi. org/10.7868/S0207352814080095 
Скибина Лилия Михайловна - к. х. Н., доцент, Южный федеральный университет; тел.: +7(904) 5054942, e-mail: skibina@sfedu.ru

Дуран Дельгадо Оскар Андрес- аспирант химического факультета Южного федерального университета; тел.: +7(989) 7197895, e-mail: duran87@yandex.ru.

Соколенко Алла Ивановна - к. х. н., доцент, Донской государственный технический университет; тел.: (863) 2738392, e-mail: asokolenko @ rambler.ru
Skibina Lilia Mikhailovna - Cand. Sci (Chem.), Researcher, Southern Federal University; ph.: +7(904) 5054942, e-mail: skibina@sfedu.ru

Duran Delgado Oscar Andrés - postgraduate student, Southern Federal University; ph.: +7(989) 7197895, e-mail: duran87@yandex.ru

Sokolenko Alla Ivanovna - Cand. Sci (Chem.), Researcher, Don State Technical University; тел.: (863 2738392, e-mail: asokolenko@ rambler.ru 